\title{
veral|s
}

ISSN 2236-5729

\section{Aspectos pedagógicos e administrativos da creche e da pré-escola catarinense}

\section{Pedagogical and administrative aspects of day care and preschool in Santa Catarina}

\author{
Verena Wiggers é graduada em Serviço Social pela Universidade \\ do Sul de Santa Catarina (1983 e em Pedagogia pela Universidade \\ do Sul de Santa Catarina. Tem mestrado em Educação pela \\ Universidade Federal de Santa Catarina, doutorado em \\ Educação:Currículo pela Pontifícia Universidade Católica de \\ São Paulo e Pós-Doutorado na Faculdade de Educação da \\ Universidade de São Paulo. Atualmente é professora no Núcleo \\ de Desenvolvimento Infantil da Universidade Federal de Santa \\ Catarina.
}

Contato: verenawi@yahoo.com.br

\section{Resumo}

0 artigo decorre de pesquisa mais ampla que teve como principal objetivo identificar os aspectos teóricos e metodológicos que fundamentam as proposições pedagógicas para a creche e a pré-escola. Para a coleta de dados utilizou-se de um questionário, com 73 questões, enviado a todos os municípios do estado de Santa Catarina. As principais conclusões apontam para a insuficiência do conteúdo apresentado nos documentos e, ainda, que o Referencial Curricular Nacional para a Educação Infantil (1998) é o documento mais conhecido e mais utilizado para subsidiar as propostas e as práticas pedagógicas em causa. A pesquisa buscou problematizar as limitações das perspectivas pedagógicas apresentadas, como também dos dados administrativos que constituem a realidade dos municípios catarinenses.

Palavras-chave: Educação. Pré-escolar. Currículo. Prática de ensino. 


\begin{abstract}
This article comes from a broader research whose goal is identify the main theoretical and methodological approaches that substantiate the educational proposals for day care centers and preschools. A questionnaire of 73 questions was sent to all municipalities in Santa Catarina to collect data. The thesis' main conclusions point out the deficiencies of most documents and also that the National Curricular Guidelines for Child Educations (1998) is the most used document to base the pedagogical practices on. The research aimed to indicate the limitations of the shown perspectives, as well as to point the necessity of the processes carried out in day care centers and preschools.

Keywords: Education. Preschool. Curriculum. Teaching practice.
\end{abstract}

\title{
Introdução
}

Em diferentes momentos de sua história, a Educação Infantil vinculou-se a vários aportes teóricos e bases epistemológicas distintas, gerando diferentes abordagens para as propostas e práticas pedagógicas desenvolvidas na creche e na pré-escola brasileira.

Em meio a esse processo histórico, a sociedade brasileira testemunhou a implantação de diversas mudanças na política educacional do país. Assim, no que se refere à Educação Infantil, observou-se, a partir da década de 1970, significativo avanço na expansão das matrículas das crianças menores de 7 anos nesse segmento, sob influência de ordenamentos sociais, tais como: processo de urbanização, crescimento econômico, lutas sociais e mudanças do papel da mulher na atual sociedade.

Com a promulgação da Carta Constitucional da República Federativa do Brasil (1988), redefiniram-se as funções social e educacional a serem incorporadas pela creche e pela pré-escola. As diretrizes legais delineadas a partir do referido marco legal destacam-se em relação às legislações anteriores, pois a Educação Infantil passou a constituir a primeira etapa da Educação Básica, tendo como finalidade o desenvolvimento da criança em seus múltiplos aspectos.

Em 1996, a nova Lei de Diretrizes e Bases da Educação (LDB 9394/96) adotou também definições fundamentais, dentre 
as quais se destaca que: a Educação Infantil é complementar à família e à comunidade; sua avaliação será feita mediante acompanhamento e registro do desenvolvimento da criança, sem objetivo de promoção ou retenção; as instituições deverão integrar o Sistema Municipal de Ensino, o Sistema Estadual de Ensino ou - Sistema Único de Educação Básica; seus profissionais também deverão ser formados de acordo com as exigências legais.

Desse modo, com o referido aporte legal, o cuidado e a educação das crianças na creche e na pré-escola ganharam a parceria e o apoio da sociedade, saindo do âmbito exclusivamente privado do contexto familiar para serem, também, da competência do Estado. Nesse novo cenário, deixaram de ser vistos como uma bondade humana e um benefício social, como concebido historicamente no contexto sociopolítico brasileiro.

Ainda que tenha alçado patamar majestoso no dispositivo constitucional, que inclui o atendimento em creches e pré-escolas entre os serviços educacionais, a configuração da Educação Infantil no cotidiano das práticas institucionais é ainda um espaço de muitas lutas, contradições e fragilidades. Desse modo, mesmo inserida no conjunto das reformas educacionais dos anos de 1990, grande parte das crianças brasileiras, sobretudo as oriundas das camadas sociais mais pobres, não tem acesso a essa forma de atendimento, ou, quando lhes é garantido esse trânsito, a qualidade dos serviços a que teriam direito nem sempre é assegurada. ${ }^{1}$

Assim sendo, os dados da realidade evidenciam que essa modalidade educativa, ao longo de sua história, se expandiu por todo o território brasileiro sem os investimentos técnicos e financeiros fundamentais para sua estruturação de forma qualificada. Consequentemente, nem sempre seus serviços se apresentam em acordo com determinados critérios de qualidade, tendo em vista que aspectos importantes vinculados a essa prática educativa estão sendo negligenciados ${ }^{2}$. Uma das fragilidades de suas muitas facetas se refere aos aspectos relacionados às propostas e às práticas pedagógicas na Educação Infantil. Conhecer o que tem sido proposto pelas redes de educação municipais no que tange à programação vinculada a creches e pré-escolas pode constituir um importante empreendimento para subsidiar as políticas públicas voltadas para essa etapa da Educação Básica. A pesquisa em causa estrutura-se em meio a esse contexto.

Ela teve como foco o estudo dos documentos-síntese de propostas pedagógicas/curriculares para a creche e para a pré-
1. Para conhecer dados relacionados à qualidade da Educação Infantil brasileira, entre outras referências, conferir Campos, Füllgraf e Wiggers (2005; 2006); Brasil (2009a); FCC (2010) 2. Ver Brasil (1996b; 2009a).. 
escola. Entretanto, por conceber que propostas pedagógicas/ curriculares são situadas e nascem de determinadas realidades e indagações, nas quais estão conjugadas múltiplas variáveis, buscouse também captar e articular na análise aspectos de natureza administrativa, política, social e econômica da realidade focada.

Essas interseções procuraram evidenciar semelhanças e/ou diferenças entre a realidade catarinense e a de outras regiões do país. Acredita-se que estudos dessa natureza contribuem para 0 debate na área e procuram lançar luz sobre os imensos desafios que ainda permanecem no campo das orientações para a prática pedagógica em creches e pré-escolas do Brasil.

Este estudo pretendeu identificar os principais aportes teóricos, conceitos e autores que servem de base para as proposições pedagógicas para creches e pré-escolas nas redes municipais de ensino do estado de Santa Catarina e as estratégias metodológicas utilizadas para a estruturação do trabalho pedagógico levado a efeito na Educação Infantil.

Suas diferentes ações pretenderam dar resposta às seguintes indagações: quais os contextos políticos, sociais e administrativos que gestaram as propostas pedagógicas analisadas? Quais foram as estratégias utilizadas para o delineamento, gerenciamento e implementação dessas diretrizes na respectiva rede municipal de ensino ou instituição de Educação Infantil? De que modo as orientações pedagógicas, políticas e administrativas vinculadas ao cenário nacional estão sendo incorporadas na diversidade de condições existentes nos municípios? Que funções sociais e objetivos são sugeridos para as ações cotidianas no atendimento de crianças em creches e pré-escolas nas diferentes redes municipais de ensino e/ou instituições?

Tal empreendimento é importante para a área, pois esses documentos constituem elementos centrais dos processos educativos, em torno do qual gravitam todas as outras atividades. A proposta pedagógica/curricular é um "projeto seletivo [...] cultural, social, político e administrativamente condicionado, que preenche a atividade escolar e que se torna realidade dentro das condições da escola, tal como se acha configurada" (GIMENO SACRISTÁN, 1998, p. 34). Constitui uma das dimensões estratégicas para que se possa captar como dada prática educacional "[...] se sustenta e se expressa de uma forma peculiar dentro de um contexto escolar [...]; o interesse pelo currículo segue paralelo com o interesse por conseguir um conhecimento mais penetrante sobre a realidade escolar" (GIMENO SACRISTÁN, 1998, p. 30). 
Assim, um currículo/proposta pedagógica pauta-se em determinados elementos advindos da sociedade e de sua(s) respectiva(s) cultura(s), constituindo, pois, "um dos meios essenciais pelo qual se acham estabelecidos os traços dominantes do sistema cultural da sociedade" (MUSGRAVE apud FORQUIN, 1993, p. 25). Além disso, a proposta pedagógica/curricular contribui para a gestão dos saberes sociais e ainda traz, no seu bojo, de forma explícita ou subjacente, concepções, valores, "especialmente aqueles relativos aos conceitos de infância, homem, educação, educação infantil, conhecimento, cultura, desenvolvimento infantil, função da instituição em relação à criança, à família e à comunidade" (KRAMER, 2001, p. 136). Desse modo, arrasta consigo concepções, valores, expectativas, sonhos. É um veículo pelo qual se explicita traços essenciais de um propósito educativo e, consequentemente, de construção de identidades sociais e individuais, constituindo material fértil para identificar o arcabouço teórico e metodológico que fundamenta as proposições pedagógicas da creche e da pré-escola.

Esse referencial é tido como importante, tendo em vista que traz implicações para a formação das novas gerações. "As teorias, diretrizes e práticas envolvidas na educação não são técnicas. São intrinsecamente éticas e políticas e, em última análise, envolvem [...] escolhas profundamente pessoais em relação [...] ao bem comum" (APPLE, 2002, p. 41). Assim, proposta pedagógica/ currículo nunca é um conjunto de conhecimentos neutros, "[...] é sempre parte de uma tradição seletiva, resultado da seleção de alguém, da visão de algum grupo acerca do que seja conhecimento legítimo. É produto das tensões, conflitos e concessões culturais, políticas e econômicas que organizam e desorganizam um povo" (APPLE, 2002, p. 59).

Nos processos educativos levados a efeito por escolas creches, pré-escolas, escolas de Ensino Fundamental e Médio -, o currículo passa a ser a "palavra-chave", pois se torna o campo de interesses e relações de dominação. Ao adquirir esse status, constitui o elemento central de análise, numa prova visível, pública e autêntica entre as aspirações, as intenções, os objetivos e os conteúdos dos processos educativos dos sujeitos sociais que se pretende formar. "A importância da análise do currículo, tanto de seus conteúdos como de suas formas, é básica para entender a missão da instituição escolar e seus diferentes níveis e modalidades" (GIMENO SACRISTÁN, 1998, p. 16).

Diante do exposto, explicita-se a relevância do citado estudo, cujo processo e resultados, para efeito deste artigo, 
foram organizados da seguinte forma: num primeiro item são apresentados os procedimentos metodológicos. Posteriormente são apresentados os principais resultados da análise dos documentos-síntese, resultantes da sistematização de propostas pedagógicas/curriculares para a creche e a pré-escola. $\mathrm{Na}$ sequência, efetua-se uma breve síntese dos resultados gerais da pesquisa e, então, são tecidas as considerações finais. Por fim, são apresentadas as referências.

\section{Procedimentos metodológicos}

Para a realização deste estudo foram utilizados, sobretudo, os documentos-síntese - publicados ou não - resultantes dos processos de delineamento de propostas pedagógicas/ curriculares, desenvolvidos no período de $1^{\circ}$ de janeiro de 2001 a $1^{\circ}$ de abril de 2006, pelas diferentes redes municipais de ensino do estado de Santa Catarina. 0 recorte cronológico relacionado aos documentos analisados tomou como base a data em que, na época, a penúltima gestão municipal tomou posse. 0 uso desse critério pretendeu garantir uma maior fidedignidade dos dados, pois sua base estaria se referindo apenas a duas gestões municipais ${ }^{3}$.

Paralelamente à citada análise, para que se captasse o contexto em que esses documentos foram gestados e implementados, bem como o modo como as orientações pedagógicas, políticas e administrativas do cenário nacional estão sendo incorporadas na diversidade de condições econômicas, sociais, políticas e culturais existentes entre os municípios, foram também colhidos dados a respeito da realidade do atendimento educacional com a ajuda de um questionário.

Esse instrumento de coleta de dados contemplou um conjunto de 73 questões - abertas ou fechadas - estruturadas em torno dos seguintes itens: Identificação; Supervisão e acompanhamento; Diretrizes pedagógicas; Aspectos diversos; e Participação da comunidade. Agregou-se também a ele a solicitação do envio de documentos-síntese resultantes do delineamento de proposições pedagógicas/curriculares para a creche e pré-escola das redes municipais e/ou outros textos que subsidiam a prática dos profissionais que atuam na respectiva rede4. Esse questionário foi entregue em mãos ou enviado pelo correio aos 293 municípios do estado, no primeiro semestre do ano de 2006. Participaram da pesquisa 73 municípios catarinenses, o equivalente a $25 \%$ de seu total.
3. 0 recorte cronológico para a coleta de dados procurou também levar em consideração o cronograma para realização das diferentes etapas da pesquisa que previa sua finalização para junho de 2007.

4. Para conhecer em detalhes 0 processo desenvolvido para a estruturação desse questionário, consultar Wiggers (2007b), p. 63 -69 . 
Finalizado o processo de coleta, os dados vinculados às questões objetivas contidas nos questionários foram organizados numa planilha excel. Já os que se vinculam às questões abertas/ dissertativas foram agrupados em instrumentos específicos criados no próprio processador de texto. Posteriormente, muitos desses dados foram organizados em gráficos ou tabelas, viabilizando, assim, sua análise. Algumas configurações e cruzamentos de dados foram realizados na Fundação Carlos Chagas (FCC).

Para viabilizar a análise dos documentos-síntese das propostas pedagógicas/curriculares disponibilizadas, por sua vez, realizouse um conjunto de procedimentos para sua sistematização e organização: estudo exploratório, mapeamento de um conjunto de categorias, configuração dos documentos por meio do programa informático Nud*ist (QSR N 5, 2000), entre outros.

Para efetuar a configuração dos dados, optou-se pelo uso do tópico como a unidade a ser utilizada nessa análise. Este é constituído pelo recorte de um dado trecho do texto que explicita determinado conteúdo vinculado a uma certa categoria, independentemente do número de palavras, frases ou caracteres.

Ao longo dessa configuração, procurou-se evitar a repetição de tópicos nas diferentes categorias. Entretanto, no decorrer da análise, percebeu-se que, em alguns deles, essa repetição se tornava fundamental, tendo em vista que muitos dos temas no interior dos documentos são abordados de forma articulada, tornando difícil o seu desmembramento. Em outras situações, foi necessário proceder à análise dos temas de forma articulada, seguindo o perfil dos documentos. Por vezes foi necessário retomar o texto original.

0 agrupamento desses tópicos em torno de determinadas categorias permitiu visualizar não apenas as diferentes concepções e aportes teórico-metodológicos apresentados e desenvolvidos ao longo dos documentos analisados, possibilitando também a identificação de recorrências, semelhanças, paradoxos e contradições entre os conteúdos explícitos e implícitos desenvolvidos ao longo dos textos. Tornou ainda possível captar um conjunto de nexos que se articulam a outros dados da pesquisa, os quais foram fundamentais para que os objetivos deste estudo fossem atingidos.

Portanto, para a realização desta pesquisa utilizou-se da análise de conteúdo para explorar os documentos-síntese, cujo procedimento exigiu o uso de várias estratégias para configuração
5. Ainda que decorrido certo tempo após a finalização desta pesquisa, considera-se prudente manter os dados do Censo Escolar utilizados na época (2005) para realização da análise, tendo em vista que estes foram utilizados para a realização de alguns cruzamentos que marcaram aquele momento da realidade brasileira e catarinense. Assim, a atualização dos dados poderia gerar descompassos entre os que foram coletados pelo questionário e os do Censo Escolar, descaracterizando a análise realizada e que, de alguma forma, marcaram aquele momento histórico e político da realidade investigada. 
dos dados contidos nos documentos, como também das demais informações de cunho quantitativo e qualitativo vinculadas ao questionário e ao Censo Escolar ${ }^{5}$.

Cabe enfatizar que, para além das citadas fontes, são desconhecidas as condições de sistematização, produção e implementação das diretrizes pedagógicas delineadas nos documentos analisados e nos dados disponibilizados.

Outro aspecto que merece ser mencionado se refere à certeza de que

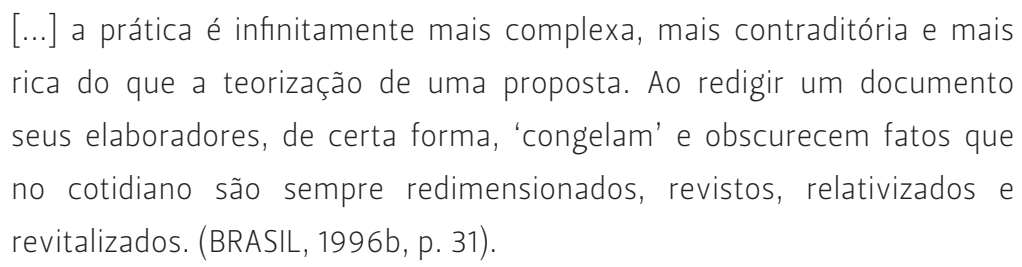

Assim sendo, ainda que reveladores, não retratam a riqueza, a diversidade, as contradições e a multiplicidade de situações encontradas nas práticas cotidianas levadas a efeito nas diferentes instituições de Educação Infantil das redes municipais de ensino que constituem esta pesquisa.

Para focar diferentes realidades e aspectos locais, no interior desta pesquisa, os municípios foram classificados de acordo com o número de habitantes, em municípios de porte muito pequeno, de pequeno, de médio e de grande portes.

Os procedimentos adotados viabilizaram a realização de um conjunto de sínteses, detalhadamente organizadas no relatório Configuração e análise dos documentos-síntese ${ }^{6}$ e na tese apresentada à Banca Examinadora da Pontifícia Universidade Católica de São Paulo, como exigência parcial para obtenção do título de Doutora em Educação no Programa de Pós-Graduação em Educação: Currículo ${ }^{7}$. Para efeitos deste artigo, pela impossibilidade de apresentar, de forma detalhada, um conjunto amplo de dados, na sequência serão apresentados os principais resultados decorrentes do estudo e análise dos documentos.

\section{Resultados da análise dos documentos}

Dos 73 municípios do estado de Santa Catarina que participaram da pesquisa, 60 afirmaram que delinearam propostas pedagógicas/ curriculares no período de $1^{\circ}$ de janeiro de 2001 a $1^{\circ}$ de abril de 
2006 e 36 municípios afirmaram que produziram documentossíntese. Todavia, apenas 17 municípios os disponibilizaram para esta pesquisa.

Os documentos analisados podem ser classificados em: projetos político-pedagógicos de instituições, diretrizes pedagógicas de redes municipais e resoluções de secretarias/conselhos municipais de Educação. Nota-se, de imediato, a diversidade da natureza dos textos disponibilizados. Por esse perfil, evidencia-se que nem todos podem ser considerados documentos-síntese de propostas pedagógicas/curriculares. Entretanto, por perceber que eles são também reveladores de um conjunto de concepções, valores, sonhos vinculados ao acolhimento de crianças em creches e pré-escolas no respectivo município, esses, após terem sido examinados no estudo exploratório, foram também incluídos nessa análise.

Estudando e analisando os documentos, podem ser identificados dois perfis distintos. Um deles demonstra preocupação de relacionar objetivos, conteúdos e atividades vinculados às diversas áreas do conhecimento, com ou sem divisão por grupo etário. Entre as divisões, a mais comum faz proposições distintas para as crianças de zero a 3 anos e para as de 4 a 6 anos de idade. Esses documentos, em geral, apresentam uma parte introdutória e argumentos em favor da apropriação/construção dos conhecimentos/conteúdos por parte da criança desde a mais tenra idade. Sugerem que a estruturação do trabalho seja realizada em torno de projetos, qualificados por permitirem a seus profissionais a organização de um conjunto de atividades que contemple os conteúdos das diversas áreas de conhecimento, tidos como fundamentais para a criança nessa faixa etária.

Assim, atribuem pouca importância às contribuições e às indicações das crianças, ainda que sejam reiteradas ao longo de um conjunto de documentos, de modo que, em um deles, os projetos a serem desenvolvidos são definidos previamente. Nessa perspectiva, argumenta-se em defesa da interdisciplinaridade ${ }^{8}$, multidisciplinaridade, transdisciplinaridade ${ }^{9}$ e da importância do desenvolvimento de temas transversais. Em geral são documentos extensos, com certo número de divisões e subdivisões, ou recortes breves, em que é priorizado um conjunto de conteúdosatividades ${ }^{10}$ a serem assegurados às crianças, constituindo-se na forma de manual a ser seguido em contraposição a diretrizes gerais a serem recriadas no cotidiano da Educação Infantil.

Esse perfil é encontrado praticamente em $50 \%$ dos documentos
8. Esse termo é empregado por 12 vezes ao longo do documento produzido por SL (sigla atribuída a um dos municípios que teve sua proposta pedagógica analisada na pesquisa).

9. Os termos, multidisciplinaridade e transdisciplinaridade são utilizados, respectivamente, por três vezes no documento intitulado SL.

10. Esse termo foi aqui cunhado e será utilizado ao longo do texto para referir-se à listagem de conteúdos a serem assegurados às crianças, mas que contém em seu interior uma mistura entre o que seriam os conteúdos e as próprias atividades a serem realizadas pelas crianças. Essa mescla parece revelar dificuldade de discernimento entre as características que os distinguem e denunciam que a atividade, por vezes, é compreendida como o próprio conteúdo a ser assegurado. 
analisados no estudo. A configuração curricular estruturou-se historicamente pela necessidade de universalização dos processos escolares e representou um avanço em relação à instrução doméstica, realizada no convívio direto com a vida dos adultos. Entretanto, há que se considerar a perda da flexibilidade no uso das estratégias a serem adotadas no trabalho pedagógico a ser efetuado às novas gerações - e, sobretudo, por voltar-se para crianças com certo desenvolvimento, e não para as de tenra idade.

Assim sendo, nota-se um inconveniente engessamento da Educação Infantil nos moldes do ensino tradicional, constituindo uma função propedêutica a escolarização posterior. Conforme assinala Kuhlmann Junior (1999, p. 57),

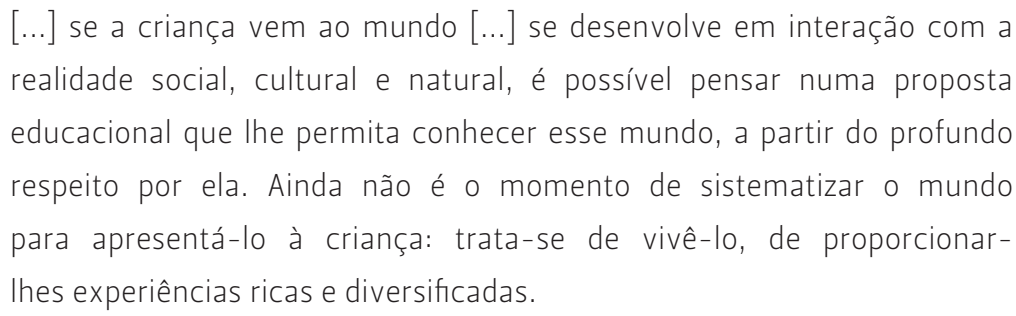

0 citado autor pondera ainda: as razões pelas quais não adotamos uma postura que trabalhe em estreita colaboração com as famílias, oferecendo "à criança um local seguro e estimulante que lhe permita plena manifestação de seu potencial físico, afetivo e intelectual, a aprendizagem de sua autonomia e de sua socialização [...] não secundarizando os aspectos relativos aos cuidados" (KUHLMANN JUNIOR, 1999, p. 57 - 58). Ele indaga também o "quão distante do bebê que vai entrar na creche está a aquisição de conceitos científicos!" (p.57).

Moreira e Silva (2002) alertam para a necessidade de desnaturalizar e historicizar o currículo, de modo a se estabelecerem arranjos curriculares alternativos e transgressores à ordem curricular existente, sobretudo no que tange a um de seus aspectos centrais: a disciplinaridade. Essa demanda decorre das próprias transformações ocorridas na produção do conhecimento. Nessa direção, criticam o papel da chamada interdisciplinaridade por supor a disciplinaridade, "deixando assim intacto exatamente o fundamento da presente estrutura" (MOREIRA; SILVA, 2002, p. 32).

Os citados autores alertam também que

[...] as noções de conhecimento, características das experiências curriculares presentemente propostas aos/às estudantes estão, também, em mais de uma dimensão, em descompasso com as modificações 
sociais, com as profundas transformações na natureza e extensão do conhecimento e também nas formas de concebê-las [...] Embora pouco saibamos sobre como essa situação pode ser modificada, podemos esperar que essa questão logo se torne uma das mais importantes no âmbito da teorização educacional crítica. Para isso é necessário que os analistas críticos se tornem menos "escolares" e mais "culturais". (MOREIRA; SILVA, 2002, p. $32-33$ ).

Assim sendo, evidencia-se que projetos pedagógicos/ curriculares que têm como centro a disciplinaridade são incompatíveis com o avanço do conhecimento e o reordenamento tecnológico. Desse modo, faz-se necessário romper com a citada estruturação curricular não apenas para as modalidades educativas compulsórias, mas, sobretudo, para crianças de tenra idade. Portanto, é indispensável lidar com categorias de currículo mais flexíveis que proporcionem experiências ricas e diversificadas, ao mesmo tempo que oportunizam às crianças a apropriação cultural de maneira ampla, e não apenas das configuradas na forma disciplinar.

0 outro conjunto de documentos procura construir/estruturar textos, desenvolvendo temáticas tidas como fundamentais para a formação profissional. Eles parecem cumprir funções distintas. Há os que pretendem sistematizar e registrar as discussões efetuadas ao longo do processo de formação, com a ampliação das discussões já efetuadas por seus profissionais, e os que pretendem subsidiar sua formação, ou seja, parece que pretendem fazer a própria formação - fragilizada na sistematização de dinâmicas e estratégias nas quais o professor possa estar presente - mediante a sistematização de textos a serem lidos e estudados individual ou coletivamente nas instituições.

Ainda que com especificidades, esse conjunto de documentos apresenta argumentos em favor do respeito à criança, à infância e à especificidade da Educação Infantil. Aponta também para a necessidade de estruturação dos espaços institucionais e para a construção de uma pedagogia para a infância e destaca a importância da estruturação do trabalho com projetos qualificados pela possibilidade de ampliação do repertório vivencial das crianças - e/ou eixos de trabalho - linguagem, interação, jogo"1; brincadeira, múltiplas linguagens, autoria e autonomia ${ }^{12}$.

No que tange a essa corrente de pensamento, nota-se que as diferentes linguagens constituem o principal conteúdo a ser assegurado às crianças. Nesse raciocínio, seriam elas que promoveriam o desenvolvimento das capacidades especificamente

11. Referenciado por dois documentos

12. Referenciado por um único documento. 
humanas. Cabe assim indagar se tal recorte não se limita a apenas um dos aspectos do desenvolvimento humano, negligenciando os demais. Em oposição à centralidade do professor, característica das práticas tradicionais, nessa perspectiva, de acordo com os documentos analisados, a criança parece adquirir competências para autogerir seu desenvolvimento e aprendizagem. Esse aspecto também merece ser questionado, pois de certa forma nega as contribuições que advêm da relação entre crianças e entre elas e parceiros mais desenvolvidos, entre os quais se destaca a atuação do professor.

Um dos documentos leva à estruturação do trabalho em torno de áreas do desenvolvimento - emoção, imitação e representação, movimento, o eu e o outro. Há também os que procuram argumentar em favor da estruturação do trabalho a partir da brincadeira e das diversas áreas de conhecimento.

Desses documentos alguns são específicos para a Educação Infantil, outros referem-se ao delineamento de diretrizes pedagógicas para as diferentes modalidades educativas mantidas pela rede de ensino. Assim, apresentam pressupostos gerais, com indicações específicas para as diferentes modalidades educativas; logo, também para a Educação Infantil. Em meio a esse conjunto, parece que nem sempre a especificidade da Educação Infantil é contemplada, tendendo a ser arrastada pelas modalidades educativas posteriores.

Entre os documentos analisados, certo número deles faz indicações específicas para a creche; entretanto essas indicações em geral se limitam à listagem distinta de conteúdos e atividades a serem desenvolvidas com a criança da creche e da pré-escola. Tal fato, parece evidenciar o reconhecimento de especificidades em diferentes faixas etárias, também parece valorizar apenas os conteúdos das diferentes áreas do conhecimento, desconsiderando a importância de levar a criança a se apropriar de valores e sentimentos pertinentes à sociedade na qual estão inseridos, bem como das ferramentas produzidas pelo ser humano e das formas de operar com elas.

Outros documentos apresentam apenas pressupostos e diretrizes bem gerais, cujas implicações pedagógicas remetem à necessidade de delineamento de ações específicas para as diferentes faixas etárias; logo, também para a creche.

Considerando o levantamento de dados efetuado pelo questionário da pesquisa, em apenas um dos municípios a creche 
vincula-se a outra secretaria que não à de Educação. Portanto, em sua maioria, os documentos foram produzidos por secretarias de Educação.

Quanto à linguagem empregada, há os que se utilizam de linguagem clara, bem fundamentada e acessível a qualquer profissional da rede, constituindo textos coerentes, coesos, bem articulados e rigorosos na utilização de citações de obras e autores. Em outros, esses critérios são desprezados, de modo que se apresentam como excertos pouco claros e objetivos, por vezes com linguagem rebuscada, carregada de jargões e, ainda, copiando trechos sem a devida citação e/ou sem a referência completa da obra. Alguns apresentam certo rigor teórico, em outros, as abordagens são claramente ecléticas. Em muitos deles são encontradas orientações para a organização das práticas cotidianas, em outros essas são precárias. Por vezes são discursos que não tocam as práticas cotidianas, constituindo "cartões de visita das administrações" (BRASIL, 1996b, p. 34).

Há de ser ressaltado, ainda, que na sistematização desses documentos pouco são utilizadas as pesquisas e os conhecimentos produzidos na área, evidenciando o quanto é difícil a incorporação deles no delineamento das políticas e das práticas pedagógicas concretas.

Nota-se que são raros os documentos que apresentam diagnóstico ampliado de suas redes, retratando a situação da Educação Infantil no que tange à "realidade socio-cultural da população a que se destina; caracterização da rede de atendimento à faixa etária entre zero a seis anos; demanda e metas de expansão; levantamento dos problemas e dificuldades enfrentados; as concepções norteadoras das práticas existentes" (BRASIL, 1996b, p. 73). Assim, trazem poucas contribuições para que se possa compreender as dificuldades, as contradições, os conflitos vividos pelas redes na implementação das ações educativas que se voltam para o acolhimento da criança na creche e na pré-escola.

Destaca-se que, dos 17 municípios, apenas quatro deles têm a preocupação de retratar, ainda que de forma breve, o percurso que levou à produção do documento que contém as diretrizes pedagógicas para a rede municipal de ensino. Dos relatos fica claro que os documentos-síntese disponibilizados decorrem da formação profissional implementada na rede e, ainda, que nesse processo foram utilizadas estratégias diversas, tais como seminários, cursos, palestras, grupos de estudos, dentre outras. 
Nenhum dos documentos aborda os conflitos e as divergências que, seguramente, constituíram o percurso que levou à sistematização desse processo e do documento escrito. Ou seja, não foram encontradas informações referentes aos desafios, tensões, conflitos, acertos e desacertos que permearam o processo de sistematização dos documentos analisados, tendo em vista a riqueza, complexidade e disputas que marcam esses processos de modo que

\section{[...] qualquer um dos sujeitos nele envolvido jamais será capaz de dizer, expressar, esgotar [...] Os processos, os movimentos da realidade, o curso da vida, da história, são sempre mais ricos que a capacidade humana de traduzir em fala, discurso, teoria [...] (PMF, 1996, p. 9).}

Eis, portanto, talvez a razão da ilusão que os documentos apresentam quanto à harmonia e à aparente tranquilidade apresentada durante o processo.

Dentre vários documentos, são encontrados argumentos em favor da flexibilidade da proposta e da possibilidade e/ ou necessidade de que essa seja reformulada e/ou ampliada. Entretanto, no texto não foram encontradas indicações que apontam para os processos de avaliação e redimensionamento da proposta, o que remete a pensar que eles constituem processos circunscritos em si mesmos, com terminalidade definida.

São poucos os documentos que explicitam, de forma clara, as razões que levaram as redes a sua elaboração e sistematização. $\mathrm{Na}$ maior parte, os argumentos apresentados mostram-se vagos, pouco articulados, constituídos de jargões, evidenciando que não se tem clareza da questão ou questões centrais a serem verdadeiramente consideradas nas ações pedagógicas que acolhem crianças na Educação Infantil. Entretanto, de forma subjacente, capta-se que esses, em geral, se voltam à oferta de subsídios aos educadores para a realização do trabalho desenvolvido, ou simplesmente para a ampliação/ redimensionamento das ações pedagógicas desenvolvidas individualmente. Desse modo, são raros os documentos que explicitam preocupação com a produção de subsídios para nortear os projetos político-pedagógicos que orientam as ações cotidianas nas instituições.

Destarte, nota-se que os interlocutores privilegiados nos documentos, ainda que não indicados explicitamente, são, em geral, os profissionais que atuam diretamente com as crianças. $\mathrm{Ou}$ seja, os professores, em suas práticas individuais, e não no coletivo 
da instituição, por intermédio da sistematização de um projeto político-pedagógico pensado coletivamente.

No que se refere à autoria dos documentos, em sete deles identificam-se claramente seus autores. Alguns relacionam o nome de consultores vinculados às universidades públicas e privadas do estado e fora dele. Outros relacionam alguns nomes e indicam que sua sistematização foi efetuada com a participação de professoras, diretores, pais, integrantes das equipes técnicas e os funcionários da Secretaria Municipal de Educação. Um deles afirma que o documento foi elaborado com a participação efetiva de todos os membros envolvidos e interessados no processo educacional da escola mediante estudos dirigidos aos professores, formação continuada e programas oferecidos pelo MEC: "Programa de Formação de Professores Alfabetizadores - PROFA" e Parâmetros Curriculares Nacionais - PCNs. Outro indica a constituição de um grupo de estudos que trabalhou na construção de uma nova proposta que levou à sistematização do documento final. Dois documentos são constituídos por textos de autorias individuais e/ ou de pequenos grupos.

Enfim, em alguns documentos a autoria é logo identificada. Em outros, parece tratar-se de processos supostamente democráticos e que contaram com a participação de quadros das secretarias e também da comunidade, ainda que não seja explicitado, de forma clara, como foram viabilizados. Em meio a essa preocupação, alguns textos acabam omitindo a verdadeira autoria - que, certamente, na sistematização final do documento, não contou com a mesma participação.

Diante desse panorama, cabe resgatar as indicações do documento do MEC (BRASIL, 1996b), no qual se alerta para a necessidade de diálogo entre o que é proposto pelos documentos e as práticas cotidianas. Assim, se faz necessário utilizar de estratégias que articulem os pressupostos delineados às dinâmicas do cotidiano. 0 uso de linguagem clara e articulada é um dos primeiros requisitos.

Igualmente, é fundamental buscar a adequação do conteúdo e a sistematização desses textos em etapas para que a dinâmica de sua estruturação contemple as vozes dos profissionais responsáveis pelo acolhimento das crianças em creches e préescolas, de modo que os professores não se apropriem apenas dos discursos ao mesmo tempo que mantenham as práticas intocadas. Do mesmo modo, recomenda-se ter cautela com sistematizações e estratégias que produzem propostas prontas para serem seguidas 
e não orientações para participantes ativos, transformadores da proposta e de sua própria prática. Essa indicação remete à obrigatoriedade do processo contínuo de formação em serviço, no qual se estabelece o intercâmbio das ideias do campo teórico com a prática cotidiana. Entretanto, distinta dessa demanda, como assevera MEC/Brasil (1996b, p. 35)

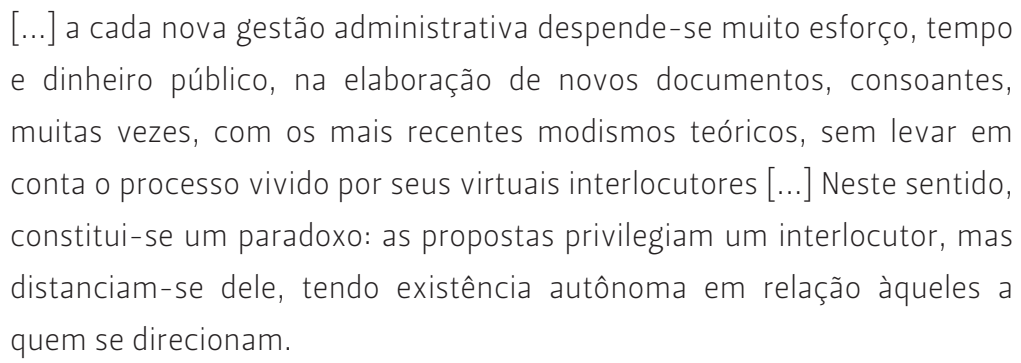

Enfim, identificam-se documentos muito bem estruturados, sistematizados e fundamentados. Em contrapartida, há os que se apresentam de forma precária quanto à linguagem utilizada, número de temas que abordam, fundamentação teórica e apresentação gráfica. Ainda assim vale destacar o mérito dessas redes e municípios, alguns de porte muito pequeno e pequeno, pela ousadia, determinação e desejo de fazer avançar o trabalho pedagógico levado a efeito em suas respectivas redes. Faz-se também necessário levar em conta que, apesar da pertinência das críticas sistematizadas ao longo deste texto, há que se considerar que eles revelam também certos avanços ocorridos na área nos últimos tempos. Do mesmo modo, evidenciam demandas a serem ainda perseguidas para sistematização do trabalho pedagógico de qualidade nos diferentes estabelecimentos estruturados nos diversos municípios catarinenses, como também em todo o território brasileiro.

No próximo item, serão apresentadas as principais considerações decorrentes da apreciação sistemática de todos os dados analisados nesta pesquisa - análise dos documentossíntese, dados coletados por intermédio do questionário e dados vinculados ao censo escolar. Assim sendo, serão também retomados, de forma breve, aspectos desenvolvidos ao longo deste texto, cuja sistematização apresentada pretendeu dar maior visibilidade aos resultados decorrentes da análise dos documentos-síntese, tendo em vista que o foco do estudo esteve voltado para os documentos-síntese decorrentes dos processos de delineamento das diretrizes pedagógicas realizadas em redes municipais catarinenses ${ }^{13}$.
13. Para conhecer de forma mais detalhada os resultados dessa pesquisa conferir Wiggers (2007b). 


\section{Breve síntese dos resultados gerais}

Por intermédio da apreciação e análise dos diferentes dados coletados, foi possível chegar a um conjunto de sínteses, cujas principais considerações serão apresentadas na sequência.

No que tange à disponibilidade de documentos-síntese, os municípios de grande porte ${ }^{14}$, ainda que minoria no estado, foram os que percentualmente mais retornaram os questionários e os disponibilizaram para a pesquisa, demonstrando que, entre esses municípios, existe maior disponibilidade de documentossíntese decorrentes do delineamento de propostas pedagógica/ curriculares para a Educação Infantil. A análise dos documentos permite também identificar que os municípios com maior contingente populacional são os que têm maior acesso ao conhecimento produzido pela área, incorporando algumas das questões que estão em debate no atual contexto dessa etapa da Educação Básica.

Entre os municípios maiores - médio e grande - todos oferecem serviços em creches e pré-escolas e há indícios de uma maior demanda por vagas em ambas as modalidades educativas. Tal razão provavelmente impulsiona a busca por formas alternativas de atendimento da demanda, a exemplo das creches domiciliares, e também do uso em maior escala das classes multisseriadas, com a presença de crianças menores de 6 anos, sobretudo na zona rural.

Quanto ao sistema de ensino municipal, verificou-se que todos os municípios de maior porte buscam constituir seus próprios sistemas. Já entre os municípios menores - muito pequenos e pequenos - encontram-se algumas opções de vinculação ao sistema estadual de ensino, conforme permite a legislação. No que se refere à integração das instituições que atendem crianças na Educação Infantil, percebe-se que entre os municípios muito pequenos, pequenos e de médio porte predominam as respostas que apontam para a vinculação de todas as instituições de Educação Infantil ao respectivo sistema de ensino. Entre os municípios de grande porte, nota-se que essa vinculação está em processo.

Os dados da pesquisa revelam ainda que as redes conveniadas e privadas sem fins lucrativos são as menos amparadas pelos serviços públicos municipais, seja no que diz respeito à distribuição de equipamentos, materiais didáticos, acompanhamento pedagógico ou formação continuada. Esta, muitas vezes, é
14. Para efeitos desta pesquisa foram considerados municípios de grande porte aqueles que apresentavam população superior a 250 mil habitantes. 
apenas contemplada com os serviços de supervisão das equipes centrais das secretarias de Educação municipais. Nota-se também uma geral falta de dados relacionados a diferentes aspectos do atendimento, evidenciando o quanto as políticas de acolhimento das crianças em creches e pré-escolas precisam ainda avançar, no financiamento, supervisão e acompanhamento das iniciativas que se voltam para o cuidado e a educação das crianças na Educação Infantil.

No que tange à estrutura e funcionamento, os serviços oferecidos em creches, pré-escolas e creches domiciliares são predominantemente vínculos estabelecidos com o setor educacional, revelando a incorporação massiva dessas modalidades aos sistemas de ensino a partir do reordenamento legal brasileiro. Constatado esse fato, delineia-se a tendência de uma maior preocupação com a formação dos profissionais e com a elaboração de orientações pedagógicas; nos diferentes municípios investigados constata-se a existência de equipe específica responsável pela Educação Infantil. Entretanto, como muitos deles apresentam número restrito de profissionais, por vezes é constituída por um único indivíduo.

A oferta dos serviços de creche e da pré-escola é efetuada predominantemente em prédio escolar de Ensino Fundamental, prédio específico de Educação Infantil, de creche ou de pré-escola, sendo pouco utilizados os espaços adaptados; o atendimento na pré-escola é uma realidade tanto na zona rural quanto na urbana; já a creche tende a predominar nas áreas urbanas; nas áreas rurais há tendência de instalação de estabelecimentos menores em comparação aos da zona urbana; em relação à demanda por vagas, há uma exigência maior por creche em período integral, e, em relação à pré-escola, predomina a demanda por vaga em período parcial.

Como critério de ingresso na Educação Infantil destacam-se os que se baseiam nas atividades laborais, seja exclusivamente da mãe ou dos pais conjuntamente. Outro critério bastante referenciado é o que favorece as famílias de menor renda per capita; para a organização dos agrupamentos, tanto para creche quanto para a pré-escola, predomina o critério idade.

Certo número dos municípios que integram a pesquisa estão situados próximos a alguma instituição de ensino superior que oferece o curso de pedagogia, sendo comum a busca de parcerias entre as redes municipais e instituições de nível superior para a realização das atividades relacionadas à formação continuada, 
cursos de formação e aperfeiçoamento, seminários, congressos. $\mathrm{Na}$ grande maioria, entretanto, trata-se de instituições privadas, o que torna essa formação dispendiosa. As dificuldades para implementação das ações voltadas para o acolhimento das crianças em creches e pré-escolas envolvem diferentes aspectos - pedagógicos, administrativos, políticos e financeiros. Observase assim que a garantia dos direitos assegurados pela legislação brasileira carece de medidas que possibilitem o equacionamento das diferentes demandas relacionadas ao atendimento da criança na creche e na pré-escola, tais como equacionamento financeiro para que se possa assegurar o acesso e a qualidade dos serviços oferecidos na creche e na pré-escola.

Para que seja possível garantir critérios mínimos para a qualidade do atendimento na creche e na pré-escola, conforme Brasil (2009d), entre outros aspectos, se faz necessário proporcionar: espaços e ambientes seguros, agradáveis e saudáveis, com rotinas flexíveis, onde as crianças possam organizar os seus jogos e brincadeiras, expressar sua sexualidade, ouvir música, cantar, dançar, expressar-se por meio de desenhos, pintura, modelagem, dramatizações e colagem. Que elas possam também: ouvir e contar histórias; interagir com as crianças maiores, menores e adultos; correr, saltar, pular, engatinhar e explorar novos ambientes; encontrar conforto e apoio sempre que precisarem; receber atenção individual, proteção e cuidado dos adultos; desenvolver sua autoestima, curiosidade e autonomia; ser tratadas sem discriminação, não serem obrigadas a suportar longos períodos de espera; ter suas famílias bem-vindas e respeitadas nas instituições; ter momentos de privacidade e quietude; locais onde possam se recostar, desenvolver atividades calmas, descansar e dormir; receber o atendimento de suas necessidades de alimentação, saúde e higiene, como também expressar seus pensamentos, fantasias, lembranças e tantas outras situações fundamentais para o desenvolvimento das novas gerações.

No que se relaciona aos profissionais com atuação direta na Educação Infantil, conforme coleta de dados efetuada por intermédio do questionário da pesquisa, eles tendem a ser chamados de professor/educador, utilizados como sinônimos; a formação prévia encontrada nos municípios catarinenses, comparativamente com a realidade nacional, apresenta níveis superiores em ambas as categorias profissionais - professores e auxiliares -, constituindo-se em realidades privilegiadas no cenário nacional; há pequena variação na formação prévia dos 
auxiliares com atuação na pré-escola comparada à creche. A mesma vantagem é percebida no que se refere à categoria professor; identifica-se que há tendência à equiparação salarial entre os professores de creche e de pré-escola; há valorização financeira dos professores/educadores em relação aos auxiliares de sala.

Tornou-se também possível identificar que, em alguns municípios, não é o professor, formado de acordo com as exigências legais, o profissional que atua diretamente com a criança, mas sim o profissional leigo, sobretudo na creche. Desse modo, evidencia-se que persistem concepções que desconsideram a importância de profissionais formados e devidamente qualificados para a atuação na Educação Infantil.

Em diferentes municípios, pôde-se identificar que, nas equipes dos órgãos centrais, não há profissionais que se dedicam exclusivamente ao acompanhamento do trabalho na creche e na pré-escola.

Destaca-se também que em apenas dois municípios investigados os professores contam com carga horária alocada para atividades complementares ao ensino; não há a devida valorização financeira, com instalação de plano de cargos e salários, em muitas das instâncias administrativas investigadas; menos da metade dos municípios investigados afirma implementar processos de formação em serviços a seus quadros; constata-se também que a presença do professor não é ainda uma realidade na creche em um número reduzido de redes, tendo em vista que, por vezes, o exercício profissional é exercido apenas por atendentes, contrastando com a realidade da maior parte dos municípios que integram a pesquisa; entre os professores especialistas predomina a atuação do professor de educação física; relacionada à razão adulto/criança, evidencia-se que há certa dispersão, indicando tanto a existência de grupos reduzidos de crianças para a faixa etária, nos quais atua certo número de profissionais que permite um acolhimento adequado à criança, quanto grupos com excessivo número de crianças e reduzido número de profissionais.

Ainda que a realidade catarinense se constitua de um quadro de formação prévia que, comparativamente a outras realidades, possa ser considerado adequado, essa é uma das dificuldades reiteradas por vários municípios. Esse fato, entre outros aspectos, evidencia que a formação prévia oferecida não responde às necessidades de qualificação requeridas para a realização do trabalho pedagógico em causa. Destarte, muitas das dificuldades não se limitam apenas 
à inexistência de quadros constituídos de profissionais habilitados, na forma da lei, mas também na inadequação dos cursos existentes às necessidades de formação para a Educação Infantil (VIEIRA, 1999; MICARELLO, 2003; KISHIMOTO, 1999). 0 desafio não se limita à simples existência de formação, mas igualmente de uma formação condizente com as demandas postas pelo desenvolvimento integral da criança.

No contexto nacional, e também catarinense, certo número de crianças com menos de 6 anos já estava matriculada no Ensino Fundamental em 2005, independentemente de este constituir-se de 8 ou 9 anos; na realidade investigada predomina o critério idade - 7 e 6 anos - para ingresso de crianças no Ensino Fundamental. Ainda assim, em dois municípios incluídos na pesquisa identificouse o uso de estratégias de avaliação e de retenção das crianças na Educação Infantil. Dessa forma, elas podem ser impedidas de ingressar no Ensino Fundamental, ao qual têm direito de serem matriculadas a partir dos 6 anos de idade.

Certo número de municípios demonstra preocupação com a articulação entre a pré-escola e a primeira série do Ensino Fundamental e busca implementar estratégias objetivando uma adequada inserção das crianças na passagem de uma modalidade educativa à outra. Conforme mostram Campos; Füllgraf; Wiggers (2005; 2006), o fato de a lei atribuir responsabilidades pela Educação Infantil e pelo Ensino Fundamental prioritariamente aos municípios deveria, em tese, facilitar essa integração.

Um significativo contingente de instituições de Educação Infantil vinculadas a diferentes redes busca formas de colaboração das famílias, caracterizadas por contribuições financeiras diretas doações - ou indiretas - participação de seus integrantes em atividades culturais; identifica-se que em certo número dos municípios a participação das famílias na gestão dos aspectos pedagógicos e administrativos da instituição está prevista na lei. Em outros, luta-se para o estabelecimento desse aporte legal, e os demais ainda não demonstram preocupação com esse aspecto; percebe-se que, além do atendimento em creches e préescolas, a maior parte dos estabelecimentos não oferece serviços complementares, sejam eles para as crianças de outras idades, sejam eles para as famílias e comunidades. Nota-se ainda que, em muitos contextos, predominam concepções negativas sobre a família, seus perfis e potencial. Em certas diretrizes, identificase um rechaço a elas, bem como dificuldades em lidar com as necessidades da família e da comunidade, impondo restrições na oferta de seus serviços e de participação nas diferentes dimensões 
de suas práticas. Esse fato revela resquícios de concepções que historicamente marcaram a Educação Infantil brasileira e indica mais uma das fragilidades da formação profissional, seja ela prévia ou em serviço.

As formas predominantes de atendimento às crianças com deficiência são feitas exclusivamente pela rede municipal de Educação Infantil, havendo articulação entre os serviços oferecidos nas unidades públicas e privadas e os serviços especializados. A distribuição de materiais didático-pedagógicos específicos para essa clientela, bem como adaptação arquitetônica dos prédios, ainda não é realidade em muitas instituições que a acolhe.

Por intermédio da análise dos dados da pesquisa tornouse possível identificar que alguns aspectos ainda apresentam resistência à introdução das mudanças delineadas pelo quadro legal brasileiro. Identificam-se, por exemplo, distorções referentes às diretrizes sobre 0 acolhimento de crianças em escolas, creches $\mathrm{e}$ pré-escolas de Santa Catarina.

A creche aparece sempre mais precária; por vezes nela trabalham apenas atendentes; apresenta menor participação no delineamento e implementação de diretrizes pedagógicas, não apresenta a mesma sistematização comparativamente à orientação e acompanhamento das ações pedagógicas pelas equipes dos órgãos centrais nem a distribuição de materiais específicos. Percebe-se também que sofre imposição do que é pensado para as crianças maiores. Sendo assim, as pré-escolas gozam de melhores condições, tanto no que tange à cobertura quanto na estrutura e funcionamento.

Relativamente às bases nas quais se pautam as diretrizes pedagógicas e os documentos utilizados pelos profissionais para organização de seus projetos político-pedagógicos e pelos professores para sistematização do trabalho cotidiano, como ainda para o delineamento das diretrizes pedagógicas para a creche e pré-escola, evidencia-se que o documento Referencial Curricular Nacional para a Educação Infantil (1998) é o mais conhecido e, supostamente, o mais utilizado para subsidiar esse conjunto de ações. As Diretrizes Curriculares Nacionais para a Educação Infantil (BRASIL, 1999) ${ }^{15}$, mandatórias, apresentam índices inferiores de utilização como subsídio para os citados procedimentos. Outros documentos oficiais importantes para a área também não gozam do mesmo prestígio.

Infere-se que a Educação Infantil na realidade investigada
15. As citadas diretrizes foram atualizadas em 2009. Assim sendo, para ter acesso a sua versão atual, conferir Brasil (2009b). 
é marcada pela "versão escolar", em sua forma tradicional. Conforme já foi indicado, essa conformação toma como eixo organizador do trabalho cotidiano os conteúdos das diversas áreas do conhecimento e vem sofrendo duras críticas da área acadêmica brasileira, que defende a necessidade de considerar as especificidades das crianças em suas diferentes faixas etárias e a função social da creche e da pré-escola. O RCNEI (1998) foi causador de polêmica na área e é tido por muitos como um retrocesso em comparação a documentos anteriores do MEC. As estratégias de divulgação e implementação, contudo, causaram grande impacto, certamente, não apenas na realidade investigada, como em muitas outras realidades brasileiras.

Os documentos analisados apresentam dois perfis distintos. Um deles demonstra preocupação em relacionar objetivos, conteúdos e atividades vinculadas às diversas áreas do conhecimento, cuja garantia se dá em torno da sistematização cotidiana efetuada pelo professor. A outra parcela de documentos procura construir/estruturar textos desenvolvendo temáticas tidas como fundamentais para a formação profissional. Eles parecem cumprir funções distintas: sistematizar e registrar as discussões efetuadas e subsidiar estudos individuais e/ou coletivos, os quais minimizam a centralidade do professor, argumentam em favor da necessidade de construção de uma pedagogia para a infância e do desenvolvimento das diferentes linguagens na criança. Ainda que em número reduzido, são também encontrados os que se utilizam de áreas de desenvolvimento.

Essas duas tendências gerais parecem reproduzir o embate entre as pedagogias diretivas, nas quais a aprendizagem resulta da instrução didática conduzida pelo professor, e as não diretivas, constituídas por uma variedade de atividades de aprendizagem iniciadas pelas crianças, apontando para uma concepção de currículo aberto para a creche e a pré-escola. Para viabilizar as aprendizagens iniciadas pelas crianças e, não pela simples instrução didática, se faz necessário que, na gestão da creche e da pré-escola, sejam contemplados: ambientes físicos - internos e externos - com ambientes estruturados e disponibilidade de brinquedos e materiais adequados a práticas pedagógicas de boa qualidade; a organização de rotinas que favoreçam a iniciativa e autonomia infantil e desestimulem períodos coletivos de ócio e espera para as crianças, contemplando as especificidade de bebês, crianças bem pequenas de creche, crianças maiores, crianças que permanecem meio período e aquelas que ficam nas instituições em período integral, dentre outros aspectos. 
Em relação a seus interlocutores, há documentos que apresentam diretrizes gerais a serem consideradas na organização dos projetos político-pedagógicos das instituições, cujas implicações remetem à necessidade de delineamento de ações específicas no interior das instituições e para as diferentes faixas etárias. Desse modo, selecionam como interlocutores os profissionais da instituição no seu conjunto. Outros procuram dialogar diretamente com o professor, indicando a necessidade de incorporação de certas diretrizes e/ou conteúdos a serem assegurados por intermédio das suas práticas individuais. Em meio a essas configurações, há os que apresentam propostas específicas para a creche e para a pré-escola. Esta, todavia, geralmente se limita à listagem distinta de conteúdos e atividades para ambas as modalidades.

Quanto ao desenvolvimento dos documentos, há os que se utilizam de linguagem clara, articulada e coesa, fundamentando suas proposições teoricamente e apresentando rigor na utilização de citações de obras e autores. Em outros, esses critérios são desprezados, de modo que se apresentam como excertos pouco claros e objetivos, por vezes com linguagem rebuscada, carregada de jargões. Em alguns deles, nota-se rigor epistemológico. $\mathrm{Na}$ maior parte, entretanto, utilizam-se de abordagens ecléticas. Raros são os documentos que apresentam coerência entre os pressupostos gerais e as orientações para a estruturação das práticas cotidianas. Em outros, as orientações que informam as práticas são quase inexistentes. Além dos diferentes perfis relacionados, identifica-se também o predomínio dos que apresentam estrangulamento entre os pressupostos gerais e as orientações para as práticas cotidianas, bem como contradições internas ao próprio documento, de modo que algumas diretrizes, por vezes, se contrapõem a outras.

Destaca-se, ainda, que na sistematização desses documentos, seus autores, no conjunto, pouco se utilizam das pesquisas e dos conhecimentos produzidos na área, evidenciando o quanto é difícil a incorporação desses conhecimentos no delineamento das políticas e das práticas pedagógicas concretas.

São raros os documentos que se empenham em retratar a história da Educação Infantil na condição de trajetória na qual estão imbricados fatores sociais, econômicos, políticos e pedagógicos, não resguardando compromisso com a história e o movimento de idas e vindas em busca de novas conquistas. É raro também, nos documentos, ver a presença de diagnósticos de suas redes, de modo que se possa compreender as dificuldades, 
contradições e os conflitos vividos por elas e suas implicações na implementação das ações educativas que se voltam para o acolhimento da criança de zero a 6 anos na creche e na pré-escola. Em geral, também não são descritos os procedimentos adotados para a sistematização dos documentos disponibilizados. Acusase significativa preocupação, na maior parte dos documentos, em afirmar que eles resultaram de processos democráticos dos quais participaram os quadros discentes e docentes das redes e/ ou instituições, ainda que as evidências dessas presenças sejam extremamente tênues ou inexistentes. Com a preocupação de demonstrar tal participação, por vezes, omitem o nome de seus autores. É unânime a omissão dos conflitos e das divergências que certamente constituíram o percurso que levou à sistematização desse processo e do documento escrito.

Em vários documentos, especialmente nos que se autointitulam ou nos que procuram incorporar pressupostos teóricos vinculados à abordagem histórico-cultural, são encontradas concepções gerais tais como homem, humanidade, sociedade, educação, desenvolvimento e aprendizagem, criança e infância. Em torno destas, agregam-se argumentos e fundamentos que enfatizam a historicidade humana. Outras concepções aparecem vinculadas ao desenvolvimento de outros temas, ou são também desenvolvidas de forma explícita: concepções de creche, préescola, professor/educador, currículo/proposta pedagógica, avaliação, planejamento, jogos e brincadeiras, leitura e escrita etc. Há também textos que se limitam a relacionar objetivos, conteúdos e atividades a serem assegurados às crianças desde a mais tenra idade.

No que diz respeito às diferentes concepções gerais desenvolvidas, nota-se que a tendência dos documentos é utilizarse dos pressupostos teóricos da psicologia histórico-cultural, indicando para a historicidade humana e da relação dialética entre desenvolvimento e aprendizagem. Há também os que conjugam a esses pressupostos os que se vinculam à abordagem construtivista, sobretudo quando desenvolvem as concepções de desenvolvimento e aprendizagem, sem se dar conta do conflito epistemológico aí suposto.

Relacionado ao aprofundamento das categorias gerais, percebese uma maior facilidade de resguardar rigor epistemológico. Quando, porém, seus autores se voltam ao delineamento das diretrizes que orientam e informam as práticas, observa-se uma dificuldade geral, na qual se torna visível a desarticulação desses pressupostos gerais com as orientações metodológicas. 
Identifica-se, por conseguinte, que o discurso de certo número de propostas explicita conceitos e tece considerações extremamente pertinentes e articuladas a concepções renovadas de homem, sociedade, educação, criança, infância, professor/ educador, educação infantil, currículo/proposta pedagógica, desenvolvimento e aprendizagem, planejamento, observação e registro, letramento/alfabetização, organização do espaço e tempo, avaliação, jogos e brincadeira, cuidado e educação, dentre outros. Ao delinear diretrizes que procuram informar as práticas, contudo, acaba rompendo com as concepções explicitadas e defendidas ao longo dos documentos.

Destarte, é usual entre eles a elaboração de certo conjunto de críticas a determinadas formas de conceber e organizar o cotidiano que se volta ao cuidado e educação de crianças de zero a 6 anos em creches e pré-escolas. No conjunto dos documentos são encontradas críticas endereçadas aos processos educativos pautados em atividades sem significação para a criança; à estruturação do trabalho a partir da ótica do adulto, sem nela considerar a criança envolvida no processo; às configurações espaciais e posturas típicas das escolas tradicionais que dificultam e por vezes impedem os processos interativos entre as crianças e profissionais; à padronização e à homogeneização das rotinas e das ações cotidianas, nas quais são imputadas a todas as crianças as mesmas atividades e situações a serem realizadas no mesmo espaço e tempo; ao conceito de "pedagógico" restrito a atividades tidas como escolares e concebidas como as que são de caráter educativo; à desarticulação das ações vinculadas ao cuidado e educação; ao uso dos jogos e brincadeiras apenas como atividades de ensino ou fruição; ao modelo de creche, na condição de espaço restrito das atividades ligadas aos cuidados, à higiene e à alimentação, e ao de pré-escola como mera preparação para o Ensino Fundamental; à "sisudez" da escola e, consequentemente, o sofrimento desnecessário no processo de aprendizagem; às práticas adotadas pelas creches e pré-escolas que concentram seus esforços prioritariamente no conteúdo de certos conhecimentos a serem transmitidos às crianças; às salas que privilegiam a presença de armários e prateleiras altas, que não permitem o acesso das crianças a brinquedos e materiais, de forma livre, sem a ajuda de um adulto; à ideia de que o "pedagógico" acontece apenas com a direção do professor/educador; à ocupação das salas dos bebês com certo número de berços, que suprimem os espaços para a exposição de materiais e desenvolvimento de movimentos livres e brincadeiras; à simples organização dos cantos temáticos e da disposição de jogos e materiais que neglig'enciam 
a presença/participação do adulto, além da repetição das ações cotidianas e sua realização nos mesmos espaços e horários, gerando rotina, homogeneizações e rituais; à colocação de brita nos espaços externos em substituição à grama; à restrição que se faz dos experimentos, misturas e outras invenções com os elementos da natureza, em especial a água e a areia; indaga-se sobre o sentido e o objetivo da decoração do espaço institucional que se utiliza de personagens estereotipados feitos pelos adultos, em substituição às produções das crianças. Por fim, alerta-se que aspectos como esses e tantos outros precisam ser questionados e repensados.

Por intermédio desse conjunto de críticas, evidencia-se a necessidade da estruturação de políticas mais adequadas à infância e o manifesto desejo e sonho de ver quebradas velhas e arcaicas perspectivas teóricas e metodológicas adquiridas pela história da Educação Infantil em diferentes contextos sociais e geográficos.

Paradoxalmente, muitos itens criticados, por vezes no interior de um mesmo documento, acabam por receber guarida no momento em que são delineadas as diretrizes que orientam e informam as práticas cotidianas, pois é recorrente nos documentos o esboço de argumentos e diretrizes que de forma explícita ou subjetiva defendem rotinas rígidas, com a padronização das ações e dos tempos que desrespeitam o ritmo e a singularidade de cada criança, bem como de práticas individuais no interior das instituições que apontam o professor de turma como o único responsável pela criança de seu grupo. Percebem-se orientações que contradizem as práticas que desenvolvem a autonomia, a autoconfiança, o espírito crítico e criativo da criança. Notase também a defesa de situações que rompem com a ideia de corresponsabilidade entre instituições de Educação Infantil e família, no cuidado e na educação da criança de zero a 6 anos, delegando à família as tarefas tidas como menos nobres. Alguns deles mostram a persistência de concepções que apontam para a necessária prontidão da criança para seu ingresso no Ensino Fundamental, trazendo para a Educação Infantil essa responsabilidade; outros defendem a creche como substituta da família e a pré-escola como propedêutica e preparatória à escolarização posterior, ora pela necessidade de desenvolver um conjunto de habilidades tidas como fundamentais, ora pela necessidade de assegurar às crianças certo conjunto de conteúdos vinculados a diferentes áreas do conhecimento. Essa última exigência também se imputa à creche. Nota-se ainda a presença de uma visão mítica das relações cotidianas travadas nas instituições de Educação Infantil. 
Em substituição às práticas e situações criticadas, há documentos que apontam para a necessidade do desenvolvimento das diferentes linguagens e das dimensões humanas potencializadas na criança, bem como para a necessidade de tomar a criança como ponto de partida para a organização das práticas pedagógicas, respeitando-a em sua particularidade e necessidades típicas do desenvolvimento.

No interior dessa corrente de pensamento, que se constrói em oposição à "versão escolar", observa-se uma visão mítica da criança, na qual, de acordo com os documentos, ela adquire poderes para autogerir sua aprendizagem e desenvolvimento. Desta forma, a atuação do professor é minimizada, incorrendo em certo espontaneísmo. Pelos argumentos encontrados nos documentos, o conteúdo a ser assegurado às crianças parece não corresponder aos conhecimentos historicamente produzidos no seu conjunto, ou à cultura geral, mas às diferentes linguagens. Nesse raciocínio, conjectura-se que seriam as diferentes linguagens que promoveriam o desenvolvimento das habilidades especificamente humanas. Diante desse fato, cabe indagar se o conceito de linguagem abarcaria o conjunto dos conhecimentos produzidos historicamente pela humanidade ou a cultura em geral.

Ainda que se concebesse como linguagem tudo quanto serve para expressar ideias, sentimentos, modos de comportamento etc., esse conceito parece ser até certo ponto estreito para designar o conteúdo dos processos educativos numa perspectiva cultural.

No interior desse debate, há que se considerar que os processos educativos precisam contemplar diferentes tipos de vivências, de modo que cada um dos sujeitos se desenvolva de forma omnilateral, e não unilateralmente. Dito de outro modo, faz-se necessário desenvolver em cada novo ser da espécie humana, por intermédio do processo ontogenético, as diferentes qualidades produzidas historicamente por meio do processo filogenético. Isso exige que se ofereça a cada criança acesso ao que há de mais desenvolvido, ou melhor, de mais complexo produzido pela humanidade, sejam esses artefatos vinculados aos conceitos e conhecimentos científicos, às diferentes linguagens ou à sensibilidade humana, tais como os sentimentos e valores éticos, estéticos e políticos. Desse modo, é preciso assegurar vivências, entre as quais, pela atividade, cada criança possa se apropriar dos diferentes instrumentos que constituem a cultura historicamente produzida e sistematizada em diversos contextos sociais e geográficos. 
Tais exigências são fundamentais por se conceber que as capacidades humanas não são naturais, tendo em vista que elas estão postas na cultura, e não no indivíduo. Assim sendo, é por meio da apropriação dos diferentes elementos da cultura que cada indivíduo desenvolve as diferentes capacidades humanas.

Tal ideário admite que a educação/ensino e o desenvolvimento estão intimamente relacionados, devendo assim constituir o mote das ações que envolvem as práticas pedagógicas desenvolvidas por escolas - creches, pré-escolas, Ensino Fundamental e Médio. Por conseguinte, para que a educação/ensino alcance seus objetivos, suas vivências precisam estar voltadas para o desenvolvimento omnilateral do ser humano, em especial no que se refere a determinadas qualidades que envolvem o desenvolvimento das suas funções psicológicas superiores - abstração, memória, representação etc.

Assim sendo, concordamos com Gimeno Sacristán (2000) quando afirma que o currículo/proposta pedagógica deve responder "aos interesses g'lobais de um modelo de ser humano e sociedade [...] que deverá ocupar-se de diferentes aspectos do ser humano, da cultura e da sociedade no momento de selecionar os conteúdos, as atividades" (p. 86 - 87).

Assim sendo, há que se pensar em uma educação geral, conferindo atenção às diferentes dimensões que constituem a humanidade em decorrência de seu processo filogenético.

\section{Considerações finais}

Ao longo da sistematização deste estudo, muitos foram os esforços empreendidos no sentido de captar um conjunto de nexos e ligações do seu objeto, tornando-se impossível, com o uso de palavras, expressar a riqueza, a complexidade e a diversidade das sínteses empreendidas no seu decorrer, grande parte das quais foram articuladas, desenvolvidas e sistematizadas na forma de textos sistematizados ao longo deste estudo. Outras ganharam novas formas e conteúdos em estudos posteriores. Diversas experiências e conhecimentos adquiridos, certamente, constituirão apenas a subjetividade desta pesquisadora. Ainda assim, terão sua importância na vida acadêmica, profissional e pessoal de quem densamente viveu esse processo.

Cabe ainda considerar que, levando-se em conta a trajetória da Educação Infantil no país e o fato de as mudanças introduzidas 
no plano legal serem relativamente recentes, é preciso não tomar as omissões, contradições, fragilidades e possíveis equívocos apontados como falhas individuais de grupos e equipes que sonharam e imaginaram novas realidades para as crianças catarinenses acolhidas em creches e pré-escolas. Dessa forma, as considerações tecidas ao longo da análise não são exaltações, censuras ou condenações pontuais, mas fazem parte do debate e do processo de reflexão crítica sobre o tema, revelando aspectos sociais, políticos, administrativos e pedagógicos frágeis e discordantes, cuja superação seguramente constitui a utopia requerida por todos aqueles que densamente vivem as contradições existentes no cotidiano da educação das crianças em creches e pré-escolas das diferentes instâncias administrativas municipais que constituem a realidade investigada e também tantas outras do estado e do país.

Ou seja, ainda que se possa tecer críticas a determinados aspectos vinculados aos documentos-síntese e dados em causa, não se pode desconsiderar sua importância e o mérito de suas redes, tendo em vista as contribuições que elas trazem para a área, na qual se está tateando para encontrar configurações mais sensatas.

Esses documentos nos ajudam a compreender as trajetórias atuais, pois estão inseridos em determinados contextos, e também a história que precisa ser contada e recriada pelos protagonistas. Para que se compreenda o seu real significado, é preciso considerar o percurso da área da Educação Infantil e a singularidade dos aspectos abordados. Assim sendo, os "equívocos" apontados e as omissões não devem ser tomados como falhas, mas como indicativos do que ainda necessita ser produzido nesse percurso. Por conseguinte, eles indicam avanços e a necessidade de alguns elementos avançarem ainda mais. Por vezes, eles se mantêm aprisionados a um percurso e a uma história, que, assim como os impulsionam, os detêm, porque a própria história e seu percurso não lhes permitiram avançar.

Elucido que os aspectos apreciados, independentemente de sua natureza, não representam louvores ou críticas endereçados a nenhuma rede individualmente; são elementos que caracterizam a área, consistindo em pontos que precisam ser mantidos, retomados, enfrentados, pensados, discutidos e superados.

Por fim, há de se pensar que, se milhões de anos não foram suficientes para produzir um resultado satisfatório, todavia a história da educação das crianças acolhidas na creche e na 
pré-escola e a contribuição das diferentes redes de educação municipal na formação dessas crianças continuarão a ser escritas nas próximas páginas. É a história das crianças pequenas e das instituições que delas se ocupam, dos profissionais que nelas atuam e dos pesquisadores que por elas se interessam.

\section{REFERÊNCIAS}

APPLE, M.W. A política do conhecimento oficial. Faz sentido a idéia de um currículo nacional? In: MOREIRA, A.F.B.; SILVA, T. T. da. Currículo, Cultura e Sociedade. $6^{a}$ ed. São Paulo: Cortez, 2002. p. 59-91.

APPLE, M.W. Repensando ideologia e currículo. In: BARBOSA, A.F.B.; SILVA, T.T. da. Currículo, Cultura e Sociedade. $6^{a}$ ed. São Paulo: Cortez, 2002. p. 39-58.

BRASIL. Constituição da República Federativa do Brasil: promulgada em 5 de outubro de 1988. $4^{a}$ ed. Organização do texto: Juarez de Oliveira. São Paulo: Saraiva, 1990a. 168 p. (Série Legislação Brasileira).

BRASIL. Lei nº 9.394 de 20 de dezembro de 1996. Lei de Diretrizes e Bases da Educação. Brasília,DF, 1996a.

BRASIL. Proposta pedagógica e currículo em educação infantil. Brasília, DF: MEC/SEF/COEDI, 1996b.

BRASIL. Ministério da Educação e do Desporto. Referencial Curricular Nacional para a Educação Infantil. Brasília: MEC/ SEF, 1998. 3 v.

BRASIL. Ministério da Educação e da Cultura, Conselho Nacional de Educação, Câmara de Educação Básica. Diretrizes Curriculares Nacionais para a Educação Infantil. Resolução n. ${ }^{\circ}$, de $7 / 04 / 1999$.

BRASIL. Ministério da Educação. Secretaria de Educação Básica. Programa Currículo em Movimento. Projeto de Cooperação Técnica Mec e Ufrǵs para Construção de Orientações Curriculares para a Educação Infantil. Brasília, 2009a. Relatório de pesquisa: Mapeamento e análise das propostas pedagógicas municipais para a Educação 
Infantil no Brasil. Disponível em <http://portal.mec.gov. $\mathrm{br} / \mathrm{dmdocuments/relat}$ _pesquisa\%20analise_ropostas_ pedagogicas.pdf>. Acesso em: $1^{\circ}$ fev. 2011.

BRASIL. Ministério da Educação. Conselho Nacional de Educação. Câmara de Educação Básica. Diretrizes Curriculares Nacionais para a Educação Infantil. Parecer homologado pelo despacho do Ministro, publicado no D.O.U. de 9/12/2009b, Seção 1, p. 14.

BRASIL. Ministério da Educação. Secretaria de Educação Básica. Política de Educação Infantil no Brasil: Relatório de avaliação. Brasília: MEC, SEB; Unesco, 2009c.

BRASIL. Ministério da Educação. Critérios para um atendimento em creches que respeite os direitos fundamentais das crianças. Brasília, DF MEC/SEF/COEDI, 2009d.

CAMPOS, M.M.; FÜLLGRAF, J.; WIGGERS, V.. Revisão das políticas e serviços da Educação Infantil no Brasil. Brasília, DF: MEC/UNESCO/OCDE: Estudos dos Municípios. Relatório final. 2005.

CAMPOS, M.M.; FÜLLGRAF, J.; WIGGERS, V. A qualidade da Educação Infantil brasileira: alguns resultados de pesquisa. Cadernos de pesquisa, v. 36, n.127, jan./abr. 2006. p. 87-128.

FORQUIN, J.C.. Escola e cultura: as bases sociais e epistemológicas do conhecimento escolar. Tradução de Guacira Lopes Louro. Porto Alegre: Artes Médicas, 1993. p. 205.

FUNDAÇÃO CARLOS CHAGAS - FCC. Educação Infantil no Brasil - avaliação quantitativa e qualitativa. Relatório Final. São Paulo, 2010. CD-ROM. Disponível em: <www.fcc.org.br/ pesquisa/eixostematicos/educacaoinfantil/pdf/relatorio_ final/pdf/>. Acesso: em 05 dez. 2011.

GIMENO SACRISTÁN, J. O currículo: uma reflexão sobre a prática. Tradução de Ernani F. da F. Rosa. $3^{a}$ ed. Porto Alegre: ArtMed, 1998. 352 p.

GIMENO SACRISTÁN, J. Educação obrigatória: o seu sentido educativo e social. Porto: Porto. 2000. p. 11- 115. 
KISHIMOTO, T.M. Política de formação profissional para a Educação Infantil: pedagogia e normal superior. Educação \& Sociedade, v. 20, n. 68, p. 61-79, dez. 1999. (Número especial: Formação de professores da educação: políticas e tendências.)

KRAMER, S., et al. Relatório de pesquisa: formação de profissionais da Educação Infantil no estado do Rio de Janeiro. Ravil, 2001. 160 p.

KUHLMANN JUNIOR, M. Educação Infantil e currículo. In: FARIA, A.L., e PALHARES, M.S. (Orgs.) Educação Infantil pósLDB rumos e desafios: polêmicas do nosso tempo. Campinas: Autores Associados, 1999. p. 51-66.

MICARELLO, H. A formação de profissionais da Educação Infantil: em foco a relação teoria e prática. In: REUNIÃO ANUAL DA ANPED, 26, 2003, Caxambu. Anais... Rio de Janeiro: ANPED, 2003.

MOREIRA, A.F.B.; SILVA, T.T. Currículo, Cultura e Sociedade. $6^{\text {a }}$ ed. São Paulo: Cortez, 2002. p. 59-91.

PREFEITURA MUNICIPAL DE FLORIANÓPOLIS. Secretaria Municipal de Educação. Coordenadoria de Ensino. Traduzindo em ações: das diretrizes a uma proposta curricular.

Florianópolis, 1996. 122 p.

VIEIRA, L.M.F. A formação do profissional da Educação Infantil no Brasil no contexto da legislação, das políticas e da realidade do atendimento. Pro-Posições, São Paulo, v. 10, n. 28, mar. 1999, p. 28-39.

WIGGERS, V. Relatório de configuração e análise dos documentos-síntese. 2007 a. 164 p. (mimio).

WIGGERS, V. As orientações pedagógicas da Educação Infantil em municípios de Santa Catarina. 2007. 259f. Tese (Doutorado em Educação: Currículo) - Programa de PósGraduação em Educação: Currículo, Pontifícia Universidade Católica de São Paulo, São Paulo, 2007b.

Recebido em: 17/08/2016

Revisto em: 30/11/2016

Aceito em: 06/12/2016

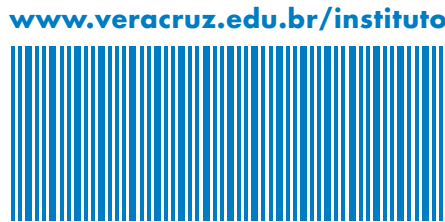

